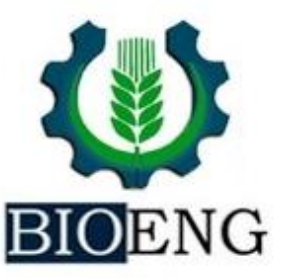

\section{UTILIZAÇÃO DA BUCHA VEGETAL DE CURCUBITÁCEA COMO MATERIAL SUPORTE EM REATOR ANAERÓBIO DE LEITO FIXO}

\author{
T. B. Magassy" , J. V. C. Fagundes, A. S. Araújo, \\ A. P. de Oliveira Netto
}

Article history: Received 13 March 2017; Received in revised form 09 May 2017; Accepted 12 May 2017 ; Available online 30 June 2017.

\title{
RESUMO
}

Este projeto avaliou o desempenho de um sistema para tratamento de esgoto sanitário operando de modo contínuo e sem recirculação da fase líquida. O trabalho se diferencia por utilizar a bucha vegetal de curcubitácea como material suporte do reator, pouco estudada para essa finalidade de tratamento biológico de efluentes. Esse material se caracteriza por ser leve, barato e facilmente encontrado na região do alto sertão alagoano, além de ser integralmente natural e com características favoráveis à imobilização de biomassa. A bucha curcubitácea vem se mostrando bastante eficiente para o tratamento de efluentes líquidos, relacionando os conceitos de sustentabilidade e eficiência. Foi utilizado um reator anaeróbio, em escala de bancada, de leito fixo e fluxo contínuo de escoamento ascendente. O desempenho do sistema foi avaliado em três diferentes tempos de detenção hidráulica (TDH), 8, 6 e 4 horas. Os valores efluentes médios para nitrogênio amoniacal foram de 22,71 $\mathrm{mg} \mathrm{N} / \mathrm{L} ; 27,97 \mathrm{mg}$ N/L; e 32,40 mg N/L para tempos de detenção hidráulica (TDH), 8, 6 e 4 horas, respectivamente. Em termos de remoção de matéria orgânica representada pela DQO, o reator apresentou eficiência média de $73,0 \%, 59,7 \%$ e 64,0\% para cada tempo estudado. Nesta pesquisa, foi desenvolvido um sistema de tratamento de esgoto sanitário estável, confiável e eficiente, em escala de bancada (experimental), baseado nos princípios do tratamento de efluentes por via biológica.

Palavras-chave: Esgoto sanitário, biomassa imobilizada, amonificação.

\section{USE OF CUCURBITACEOUS BUSH AS SUPPORT MATERIAL IN ANAEROBIC FIXED BED REACTOR}

\begin{abstract}
The project evaluated the performance of a continuous domestic sewage treatment system. The work is distinguished by using the cucurbitaceous vegetable bush as support material, little studied for this purpose of biological treatment. This material is characterized by being light, cheap and easily found in the region of study, besides being natural and with characteristics favorable to the biomass immobilization. The cucurbitaceous bush has been shown very efficient for the treatment of effluents, relating the concepts of sustainability and efficiency. An anaerobic fixed bed reactor, in bench scale, with continuous stream flow rate was used. The system performance was evaluated in three different hydraulic retention times (HRT), 8, 6 and 4 hours. The mean effluent values for ammoniacal nitrogen were $22.71 \mathrm{mg} \mathrm{N}$ / L; $27.97 \mathrm{mg} \mathrm{N} / \mathrm{L}$; and $32.40 \mathrm{mg} \mathrm{N} / \mathrm{L}$ for hydraulic retention times (HRT), 8, 6 and 4 hours, respectively. In terms of organic matter removal represented by COD, the reactor had an average efficiency of $73.0 \%, 59.7 \%$ and $64.0 \%$ for each time studied. In this research was
\end{abstract}


developed a stable, reliable and efficient sewage treatment system, based on the principles of biological treatment.

Keywords: Sewage, immobilized biomass, ammonification.

\section{INTRODUÇÃO}

É de conhecimento comum a importância da água para a garantia da boa qualidade de vida em todo o mundo. Esse é um tópico que nas últimas décadas vem sendo cada vez mais discutido e estudado em todos os lugares e com a devida razão, pois um sistema regular e eficiente de abastecimento de água, coleta e tratamento de esgoto traz inúmeros benefícios à sociedade, principalmente no que diz respeito à economia e saúde pública. Um estudo realizado por Hulton e World Health Organization (2012) relata que as perdas mundiais associadas ao inadequado abastecimento de água e saneamento são estimadas em 260 bilhões de dólares por ano. Além disso, os mesmos autores concluem que para cada dólar investido em intervenções necessárias na área de saneamento existe, em média, uma economia global de 5,5 dólares. De acordo com Uhr et al. (2016), a prevenção das principais endemias adquiridas por veiculação hídrica está relacionada, principalmente, à quantidade de domicílios atendidos pela rede coletora pública de esgotos, além do número de domicílios com coleta de lixo. Quanto mais eficientes forem esses serviços, menor será a ocorrência dessas doenças. Ainda assim, os autores afirmam que um aumento de $1 \%$ no percentual de gastos com saúde reduziria $3,16 \%$ das taxas de internações hospitalares. Tais números são expressivos e nos mostram a necessidade investimentos na área de saneamento ambiental.

Buscando aprimorar os serviços de saneamento básico, pesquisas na área de tratamento de esgotos se destacam cada vez mais no cenário global, onde são propostos e desenvolvidos novos modelos e tecnologias que podem ser implementados na sociedade buscando o controle e prevenção de doenças, facilitar a atividade econômica e melhorar a produtividade do indivíduo (OLIVEIRA NETTO e ZAIAT, 2012). No Brasil, infelizmente a situação ainda está longe da recomendável, pois cerca de $46,2 \%$ da população tem acesso à coleta de esgoto, onde apenas $37,9 \%$ do mesmo é tratado (SNIS, 2011). O esgoto (in natura) que não é coletado pela rede é recebido por rios e mares, prejudicando o meio ambiente por contaminar as águas que são utilizadas para abastecimento, irrigação e recreação (IBGE, 2000)

$\mathrm{Na}$ busca pelo tratamento de esgoto sanitário, o primeiro passo é decidir entre duas possíveis formas: o tratamento físicoquímico ou o biológico. Por ser um sistema sustentável e de baixo custo operacional, a segunda opção é considerada a mais viável a ser explorada e aprofundada. Trabalhando com sistemas biológicos, existem as formas aeróbias e anaeróbias de tratamento de efluentes, e, dependendo do caso, uma pode ser mais eficaz que a outra, porém não é possível afirmar a melhor entre as duas. De acordo com Rodrigues et al. (2016), o processo anaeróbio é interessante pois produz uma reduzida quantidade de sólidos, consome pouca energia, apresenta baixo custo de implantação e operação, além de tolerar elevadas cargas orgânicas

O tratamento anaeróbio é um processo biológico que trabalha com a ausência de oxigênio, representando um sistema natural e delicadamente balanceado, no qual cada um dos microrganismos tem uma função específica no tratamento (METCALF \& EDDY, 2013), onde as bactérias presentes são capazes de degradar os compostos orgânicos, convertendo-os em gás metano (60 a 70\%), dióxido de carbono $\left(\mathrm{CO}_{2}\right)(40$ a 30\%), além de outros subprodutos mineralizados (SOUZA, 2001). 
A ação dessas bactérias no tratamento está diretamente relacionada com o material suporte no interior do reator, que permite a imobilização celular. Em busca de inovar e utilizar um material não convencional que associe sustentabilidade com eficiência no tratamento biológico de efluentes, analisou-se nos últimos anos a eficácia da bucha vegetal de curcubitácea para essa finalidade, um material integralmente natural e com propriedades favoráveis, e o resultado vem sendo muito satisfatório, atingindo níveis em torno de 90,2\% e 26,8\% para remoção de matéria orgânica, em termos de DQO filtrada, e conversão de nitrogênio amoniacal, respectivamente.

A bucha vegetal de curcubitácea, ou Luffa cylindrica é um material com aparente alta porosidade, de boa rugosidade e de baixo custo, sendo facilmente encontrada na região do alto sertão alagoano. Suas características naturais promovem a adesão da biomassa e permitem um comportamento hidrodinâmico estável, homogeneizando o

\section{MATERIAIS E MÉTODOS}

Para realização dos experimentos foi utilizado reator de leito fixo e escoamento ascendente, operado de modo contínuo, apresentado na Figura 1, o qual foi operado em fase anaeróbia. $\mathrm{O}$ reator foi mantido em temperatura ambiente durante toda a sistema e, consequentemente, aumentando sua eficiência, pois os suportes inertes para imobilização da biomassa favorecem a estabilização (SHOW, 1999), e os reatores que contém células imobilizadas são menos suscetíveis à presença de materiais tóxicos e inibidores que os processos que utilizam a biomassa suspensa, de acordo com Stevens (1988).

Diante disso, o projeto analisou um sistema anaeróbio para o tratamento de esgoto sanitário proveniente do Campus do Sertão da Universidade Federal de Alagoas. Em escala de bancada, o sistema dispôs de um material suporte barato e de fácil obtenção na região do semiárido alagoano, a bucha vegetal de cucurbitácea, visando à observação da remoção da matéria orgânica e nitrogênio. Assim, buscou-se especificamente avaliar a influência da redução do tempo de detenção hidráulica (TDH) e comprovar eficiência da bucha vegetal de curcubitácea como material suporte para o reator biológico.

operação e recoberto com papel alumínio, para evitar a incidência direta da luminosidade e crescimento de microrganismos fotossintetizantes indesejáveis ao processo. 


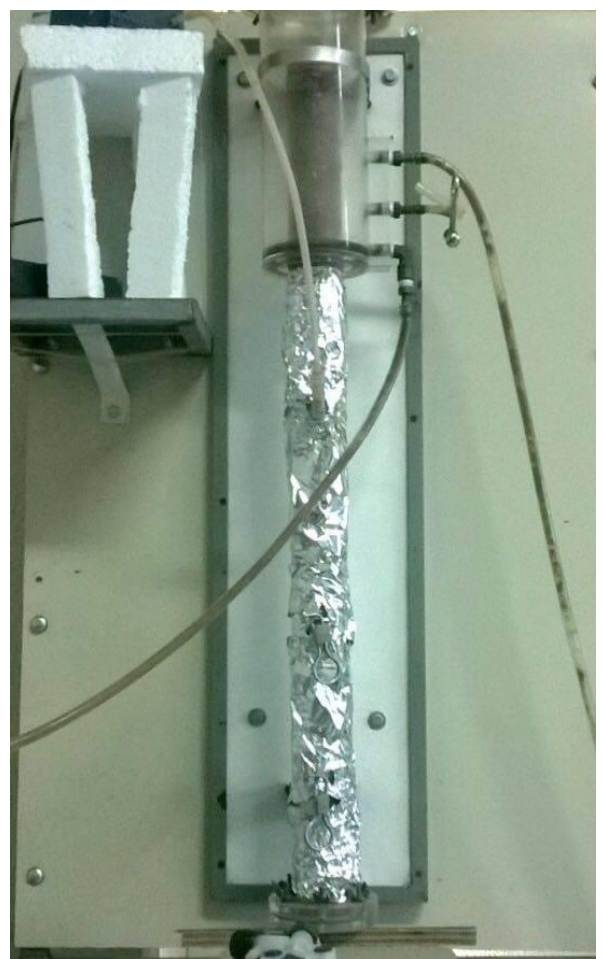

(a)

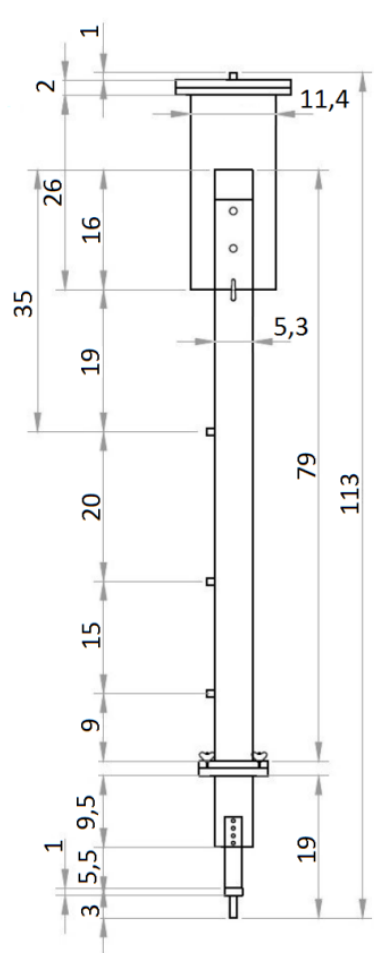

(b)

Figura 1: (a) Reator recoberto com papel alumínio. (b) Projeto do reator dimensionado em centímetros.

A composição do sistema é basicamente feita em duas partes: câmara de alimentação e distribuição de água residuária e leito reacional. A alimentação foi feita pela parte inferior do reator por meio de bomba dosadora tipo diafragma com fluxo em pulso. O material suporte utilizado foi a bucha vegetal de cucurbitácea, encontrada facilmente na região do alto sertão nordestino, pouco estudada para essa finalidade de tratamento biológico de efluentes (Figura 2). As buchas foram cortadas em cubos de aproximadamente $1 \mathrm{~cm}$ de lado para se adequarem a escala do reator utilizado, permitindo uma maior homogeneização do material no interior do reator.

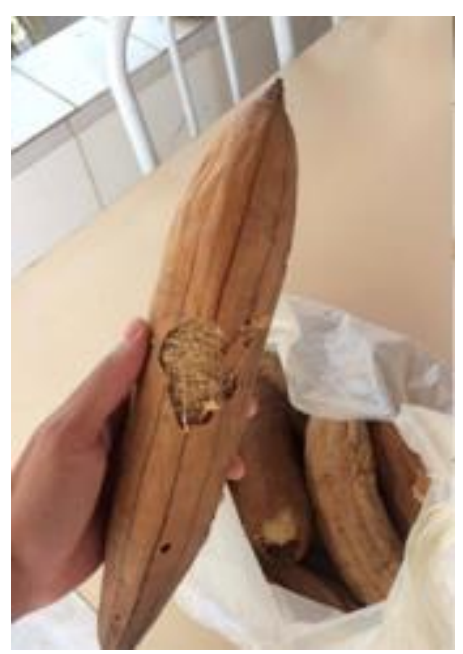

(a)

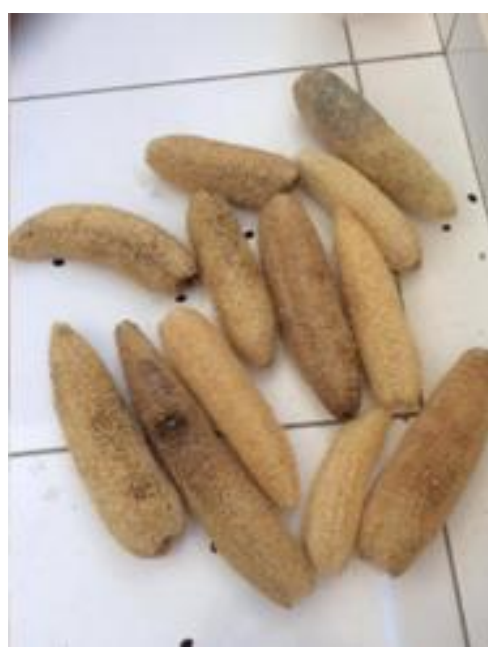

(b)

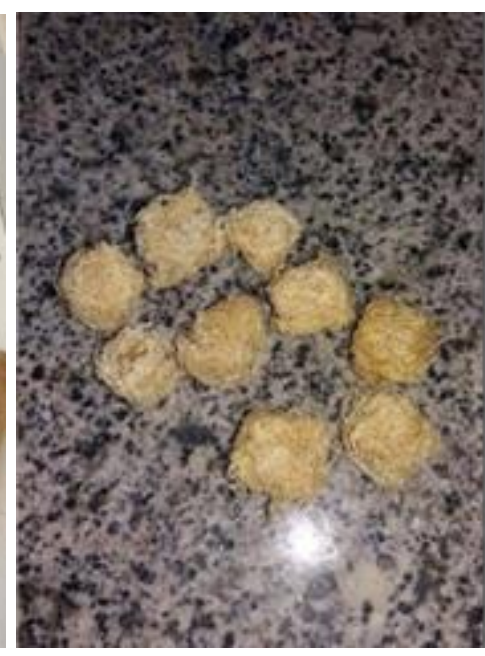

(c)

Figura 2: Bucha curcubitácea natural (a). Bucha descascada (b). Corte em cubos (c).

Inicialmente houve a inoculação, onde $\mathrm{o}$ reator ficou em regime de recirculação por um dia, com lodo anaeróbio proveniente de sistema em 
operação, para possibilitar maior agregação de biomassa e, consequentemente, acelerar o processo de adaptação e eficiência de tratamento. Então, iniciou-se a operação, em fase anaeróbia, com TDH de $8 \mathrm{~h}$, passando para $6 \mathrm{~h}$ e, por fim, 4h. O tempo total de operação foi de 105 dias, sendo 52 dias para a primeira fase $(\mathrm{TDH}=8 \mathrm{~h}), 36$ dias a segunda $(\mathrm{TDH}=6 \mathrm{~h})$ e 17 dias para a fase final $(\mathrm{TDH}=4 \mathrm{~h})$.

$\mathrm{O}$ esgoto afluente antes de chegar ao reator passou por um reservatório, o qual funcionou como tanque de equalização. Esse reservatório foi um barrilete, sendo abastecido diariamente, de maneira que a água residuária foi sempre renovada. Antes do esgoto chegar ao barrilete, o mesmo passou por um peneiramento logo no momento da coleta, para retenção dos sólidos mais grosseiros, recebendo $\mathrm{O}$ esgoto já pré-tratado. Então, a alimentação do reator foi feita a partir do bombeamento do esgoto contido nesse reservatório. As amostras eram coletadas duas vezes por semana na entrada (afluente) e saída (efluente) do reator, e eram congeladas para posteriores análises laboratoriais.

Essas análises laboratoriais eram feitas de acordo com os parâmetros listados na Tabela 1, segundo os métodos descritos pela APHA (1998). Ácidos voláteis totais (AVT), expressos como ácido acético (HAc), foram analisados de acordo com metodologia descrita por Dilallo \& Albertson (1961) e alcalinidade, expressa como $\mathrm{CaCO}_{3}$, conforme metodologia descrita por Dilallo \& Albertson (1961) e modificada por Ripley et al. (1986).

Tabela 1. Parâmetros Analisados, método utilizado e frequência de amostragem.

\begin{tabular}{|c|c|c|}
\hline Parâmetro analisado & Método de análise & Frequência de amostragem \\
\hline Vazão & & Diária \\
\hline Alcalinidade $\left(\mathrm{mg} \mathrm{CaCO}_{3} / \mathrm{L}\right)$ & Titulométrico & $2 \mathrm{x}$ semana \\
\hline Ácidos voláteis (mg HAc/L) & Titulométrico & $2 \mathrm{x}$ semana \\
\hline $\mathrm{pH}$ & Potenciométrico & $4 \mathrm{x}$ semana \\
\hline DQO Bruta (mg/L) & Espectrofotométrico & $2 \mathrm{x}$ semana \\
\hline Sólidos Totais (ST) & Gravimétrico & $2 \mathrm{x}$ semana \\
\hline Sólidos Suspensos Totais (SST) & Gravimétrico & $2 \mathrm{x}$ semana \\
\hline $\mathrm{N}-\mathrm{NH}_{4}^{+}(\mathrm{mg} \mathrm{N} / \mathrm{L})$ & Titulométrico & $2 \mathrm{x}$ semana \\
\hline
\end{tabular}

\section{RESULTADOS E DISCUSSÃO}

Os resultados apresentam o comportamento do sistema de tratamento através dos três tempos de detenção hidráulica previstos na metodolgia. A vazão foi medida diariamente, no intuito de manter as condições operacionais, e teve valor médio de $3,5 \mathrm{~mL} / \mathrm{min}$, $5,0 \mathrm{~mL} / \mathrm{min}$ e $6,2 \mathrm{~mL} / \mathrm{min}$, respectivamente, para TDH de 8,6 e 4 horas.

Os valores provenientes das análises em laboratório para Ácidos Voláteis Totais com TDH de 8,6 e 4 horas podem ser encontrados na Figura 3. Nela constam os valores obtidos para as amostras de afluente e efluente coletados durante a fase experimental, e segundo os parâmetros previstos no projeto encontram-se de acordo com o esperado. Os melhores resultados obtidos foram para o TDH de 8 horas, conforme análise do gráfico da Figura 3. 


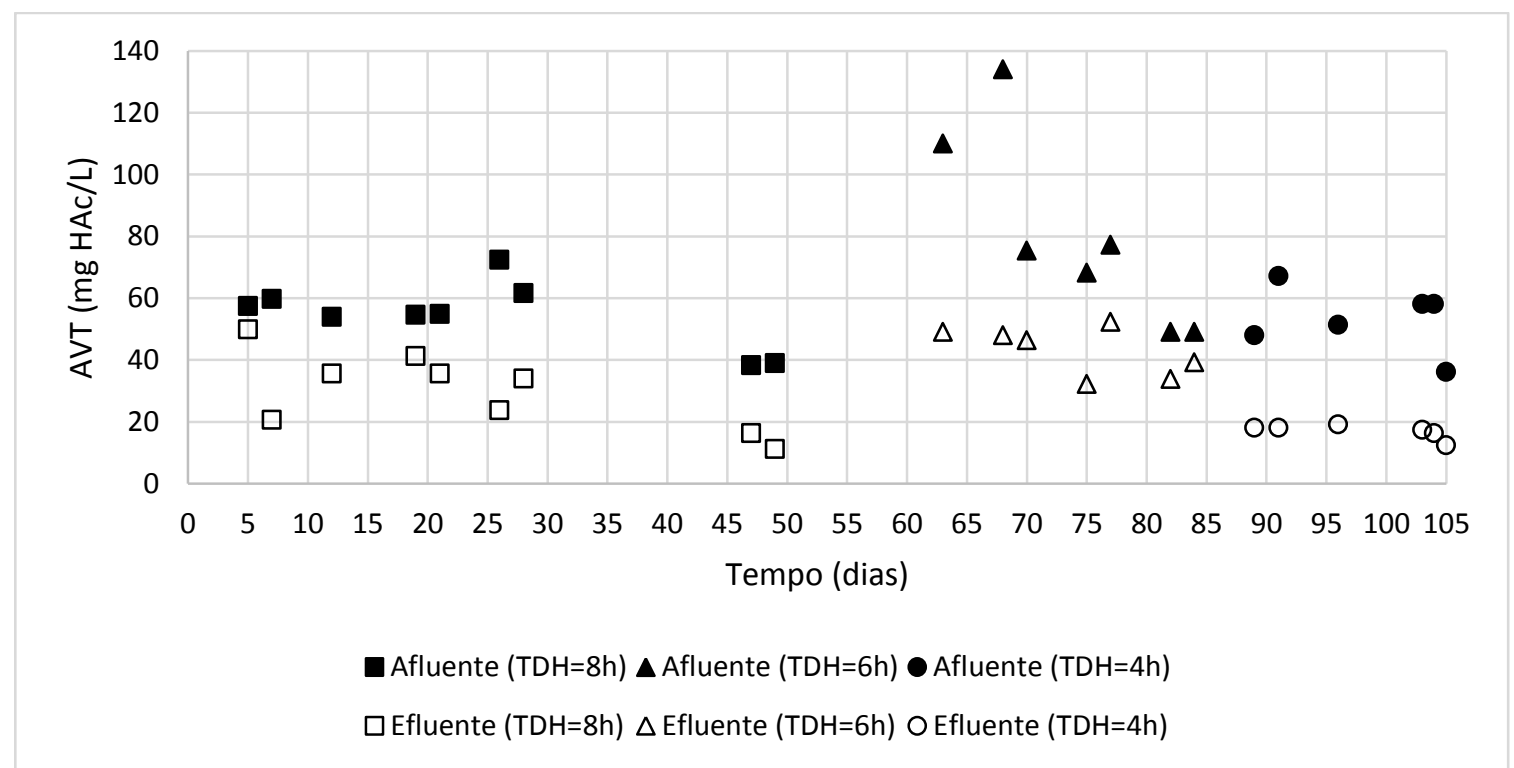

Figura 3. Ácidos Voláteis Totais para TDH de 8, 6 e 4 horas.

É possível constatar que desde o primeiro dia operacional $\mathrm{o}$ valor $\mathrm{da}$ concentração de AVT do efluente foi menor que o do afluente, o que indica equilíbrio do processo de conversão anaeróbia da matéria orgânica. Pode-se afirmar que este resultado era esperado devido à inoculação da bucha com lodo anaeróbio proveniente do sistema de tratamento.

Para as análises de alcalinidade, expressa como $\mathrm{CaCO}_{3}$, os valores obtidos para os TDH de 8,6 e 4 horas são apresentados na Figura 4 e também foram satisfatórios, possuindo, mais uma vez, os melhores resultados no TDH de 8 horas.

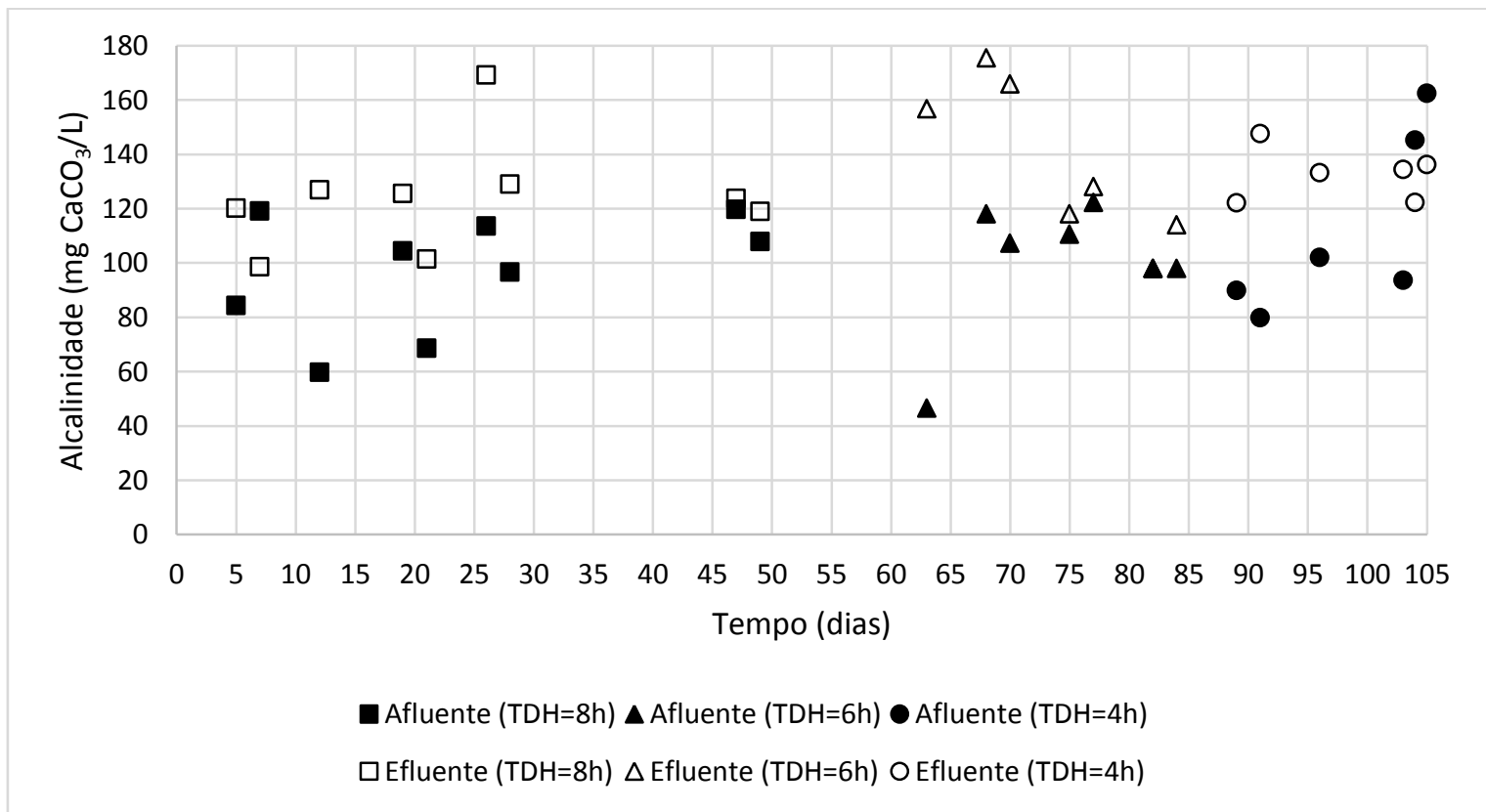

Figura 4. Alcalinidade para TDH de 8, 6 e 4 horas.

Em quase todo o processo, como pode ser observado na Figura 4, a alcalinidade a bicarbonato foi maior no efluente que no afluente. Essa geração de alcalinidade mostra o equilíbrio bioquímico entre microrganismos metanogênicos e acidogênicos/acetogênicos. A ressalva está na segunda amostra para o TDH de 8 horas, onde o sistema provavelmente estava em processo de adaptação, mesmo após inoculação, por estar no início da 
operação, e possivelmente esse fator colaborou para o valor fora do esperado. A alcalinidade também passou a ser consumida na última fase de operação, com tempo de detenção de 4 horas, quando nas duas últimas amostras o valor da alcalinidade a bicarbonato afluente tornouse superior a do efluente, evidenciando um possível princípio de limite operacional para o sistema proposto. Apesar disso, a análise dos resultados da variação temporal de alcalinidade e ácidos voláteis é capaz de demonstrar a estabilidade do reator durante as fases da operação.

A medição do Potencial Hidrogeniônico $(\mathrm{pH})$ foi realizada conforme a Tabela 1, onde os resultados obtidos das amostras coletadas são explicitados na Figura 5 a seguir. Pode-se observar que durante a maior parte do experimento, o $\mathrm{pH}$ efluente foi maior que o afluente, o que confirma as afirmativas anteriores de o processo estar ocorrendo de forma estável, sem acidificação do meio.

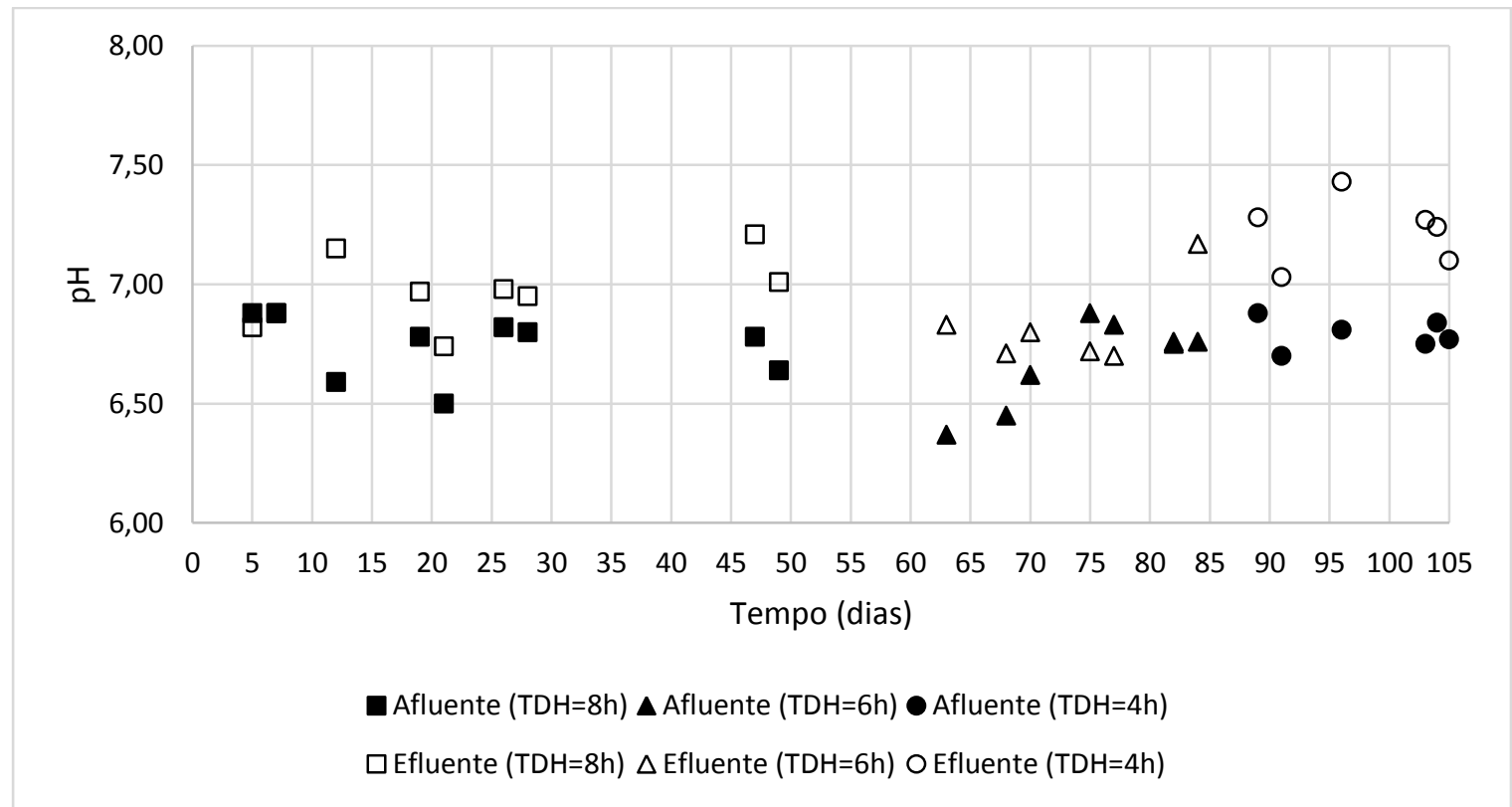

Figura 5. pH para TDH de 8, 6 e 4 horas.

Em busca de verificar a eficiência do reator no que diz respeito à remoção de matéria orgânica, foi feita análise de DQO Bruta. Percebe-se na Figura 6 que a DQO efluente foi menor que a afluente desde o início da operação, o que mostra a eficácia na remoção da matéria orgânica. As médias de remoção de matéria orgânica para o TDH de 8, 6 e 4 horas, respectivamente, foram de $73,0 \%, 59,7 \%$ e $64,0 \%$, mais uma vez associando os melhores resultados ao TDH de 8 horas. Abreu e Zaiat (2008) utilizaram um reator similar também de maneira anaeróbia, com espuma de poliuretano como material suporte, para os TDH de 8 e 6 horas o obtiveram, respectivamente, $37,0 \%$ e $46,0 \%$ de remoção de matéria orgânica. Isso nos mostra uma maior eficiência na bucha vegetal curcubitácea como material suporte. 


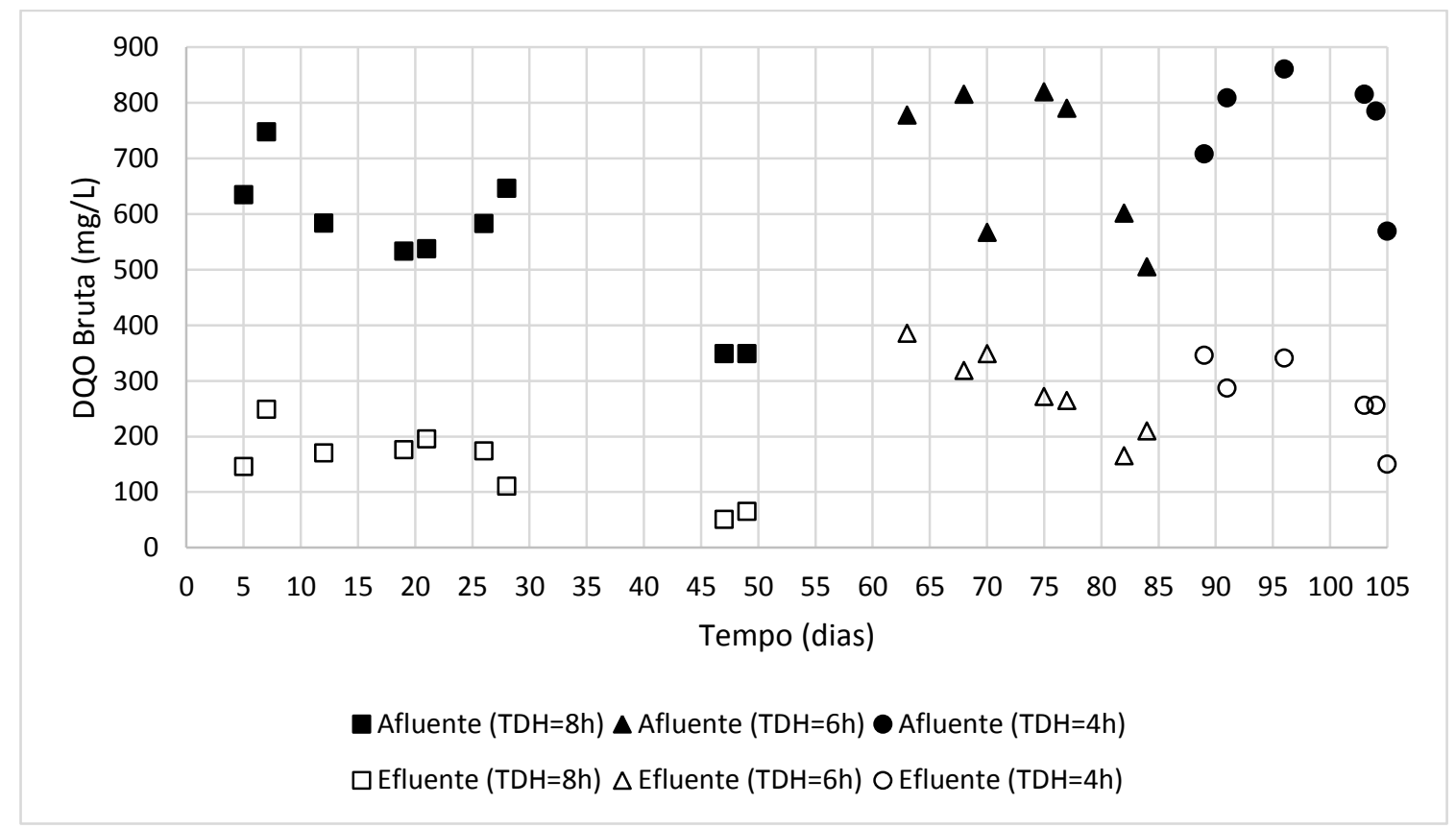

Figura 6. DQO Bruta para TDH de 8, 6 e 4 horas.

Para análise dos ST e SST, as Figuras 7 e 8 mostram a distribuição temporal destes parâmetros. Para os Sólidos Totais, a Figura 7 fornece os resultados das amostras coletadas. Houve remoção de $38,1 \%, 36,0 \%$ e $43,6 \%$ para os TDH de 8, 6 e 4 horas, respectivamente, enquanto os resultados para Sólidos Suspensos Totais, dispostos na Figura 8, para os respectivos TDH de 8,6 e 4 horas, apontam reduções de 56,2\%, 81,6\% e $45,32 \%$. Para redução do TDH é necessário aumentar a vazão de alimentação do sistema e,

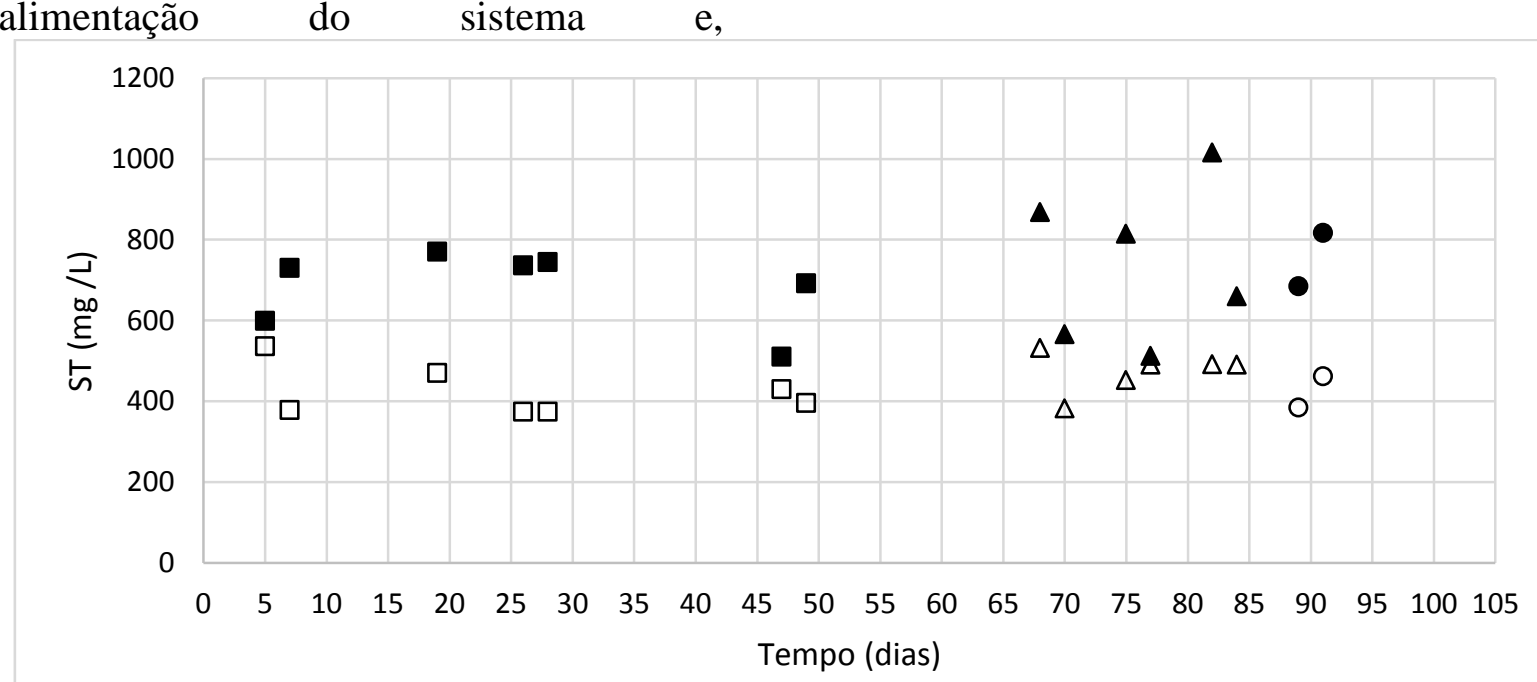

afluente $(T D H=8 h) \Delta$ Afluente $(T D H=6 h) ~ A$ Afluente $(T D H=4 h)$

$\square$ Efluente (TDH=8h) $\Delta$ Efluente (TDH=6h) O Efluente (TDH=4h)

Figura 7. ST para TDH de 8, 6 e 4 horas. consequentemente, as velocidades ascensionais no leito reacional. O maior contato entre substrato e microrganismos pode melhorar as eficiências de remoção de matéria orgânica, pela ação da transferência de massa, mas seu excesso traz problemas de arraste de sólidos provocando efeito adverso. Observando os resultados da pesquisa, pode-se constatar menor remoção de SST para o TDH de 4h, o que também influi negativamente na eficiência de remoção de matéria orgânica. 


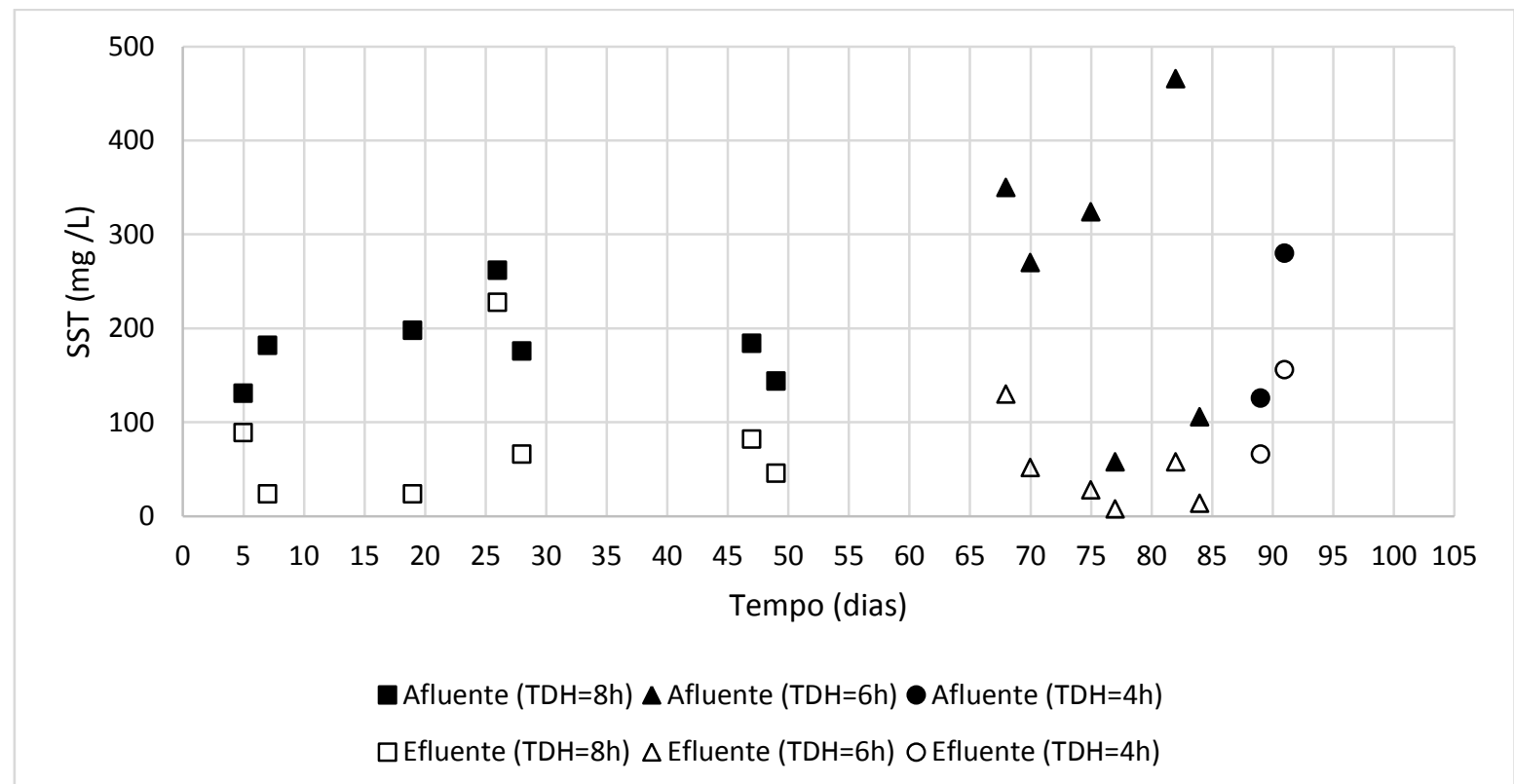

Figura 8. SST para TDH de 8, 6 e 4 horas.

O nitrogênio no esgoto sanitário de origem predominantemente doméstica, como é o caso desta pesquisa, encontra-se, quase que totalmente, sob a forma orgânica e amoniacal. A fração orgânica é formada principalmente por proteínas, aminoácidos e ureia. Por meio de reações de hidrólise, a ureia proveniente da urina é transformada em N-amoniacal. A decomposição biológica do material fecal converte as proteínas, aminoácidos, entre outros, em nitrogênio amoniacal. Esses processos são denominados de amonificação (FAZOLO, 2003). O processo de amonificação depende da parcela de N-orgânico presente nas águas residuárias. Metcalf \& Eddy (2013), afirmam que quando se trata de esgotos sanitários, a amonificação é praticamente sempre a etapa limitante do processo de nitrificação.
Nos sistemas biológicos anaeróbios, a remoção de nitrogênio total comumente observada pode ser atribuída principalmente à assimilação dos compostos amonificados para síntese celular, rotas metabólicas alternativas e armazenamento devido a estresse metabólico. Embora uma parcela de nitrogênio amoniacal possa ser assimilada para formação de novas células, sua importância na remoção de nitrogênio é limitada. Por isso, em processos biológicos com remoção de nitrogênio, os fenômenos da nitrificação e desnitrificação são considerados preponderantes. A Figura 9 apresenta dados de concentração de nitrogênio amoniacal no afluente e efluente para toda operação da fase anaeróbia. 


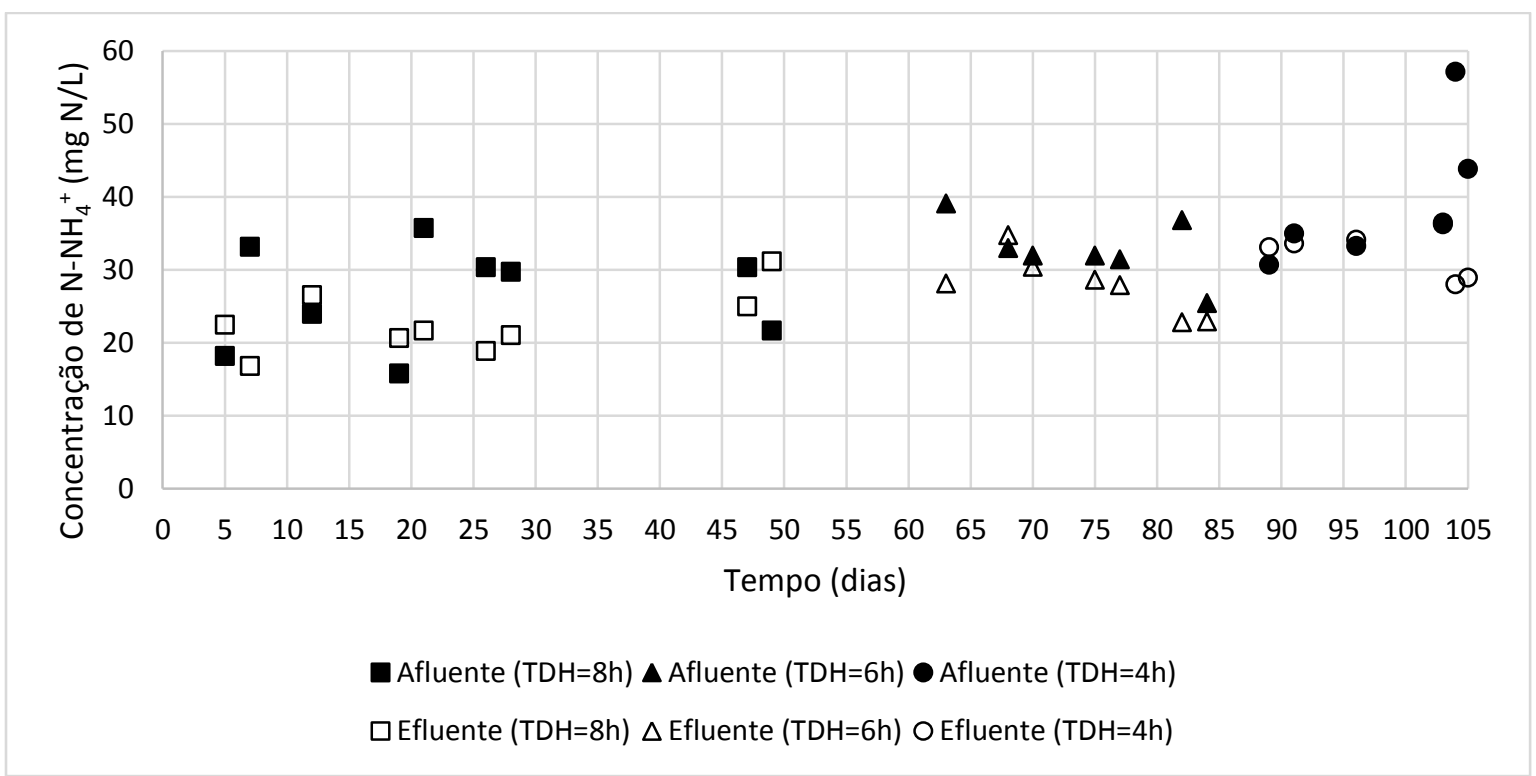

Figura 9. Concentração de nitrogênio para diferentes TDH.

A partir dos parâmetros que foram observados durante toda a fase experimental, a análise dos dados mostrou que o TDH de oito horas permite uma maior eficiência no tratamento de efluentes com o reator que se utiliza de tecnologia anaeróbia. Os melhores resultados obtidos para a formação do $\mathrm{N}$-amon (amonificação) foram para o TDH de 8 horas com média de $34,7 \%$ de conversão de nitrogênio. Para operação com TDH de 6 horas a conversão teve média de $17,0 \%$ e de $29,6 \%$ para operação com 4 horas. A seguir a Tabela 2 compila os dados médio de toda a operação do sistema.

Tabela 2. Compilação de resultados médios obtidos para cada parâmetro nos diferentes TDH.

\begin{tabular}{ccccccc}
\hline \multirow{2}{*}{ Parâmetro } & \multicolumn{2}{c}{ TDH $=\mathbf{8}$ h } & \multicolumn{2}{c}{ TDH $=\mathbf{6 ~ h}$} & \multicolumn{2}{c}{ TDH $=\mathbf{4 ~ h}$} \\
& Afluente & Efluente & Afluente & Efluente & Afluente & Efluente \\
\hline AVT & $54,7 \pm 7,3$ & $29,9 \pm 10,5$ & $80,5 \pm 23,8$ & $41,3 \pm 6,8$ & $53,8 \pm 8,0$ & $17,8 \pm 1,7$ \\
Alcalinidade & $97,1 \pm 17,6$ & $123,8 \pm 12,4$ & $100,1 \pm 16,5$ & $136,7 \pm 25,2$ & $112,2 \pm 27,8$ & $132,6 \pm 7,0$ \\
pH & $6,74 \pm 0,11$ & $6,97 \pm 0,11$ & $6,67 \pm 0,16$ & $6,81 \pm 0,11$ & $6,79 \pm 0,05$ & $7,23 \pm 0,11$ \\
DQO & $551,4 \pm 97,2$ & $148,8 \pm 49,2$ & $696,6 \pm 122,2$ & $280,8 \pm 67,2$ & $757,9 \pm 98,8$ & $272,8 \pm 47,9$ \\
ST & $683,0 \pm 73,4$ & $422,6 \pm 48,1$ & $739,3 \pm 160,0$ & $473,0 \pm 37,3$ & $750,0 \pm 66,0$ & $423,0 \pm 39,0$ \\
SST & $182,4 \pm 27,6$ & $79,9 \pm 45,6$ & $262,3 \pm 120,2$ & $48,3 \pm 31,7$ & $203,0 \pm 77,0$ & $111,0 \pm 45,0$ \\
$\mathrm{~N}^{-N H_{4}}{ }^{+}$ & $26,6 \pm 5,9$ & $22,7 \pm 3,2$ & $32,8 \pm 3,0$ & $28,0 \pm 2,9$ & $39,4 \pm 7,4$ & $32,4 \pm 2,6$ \\
\hline
\end{tabular}

Ácidos Voláteis Totais (AVT) expresso em mg HAc/L; Alcalinidade é expressa em $\mathrm{mg} \mathrm{CaCO} / \mathrm{L}$; DQO bruta, Sólidos Totais (ST) e Sólidos Suspensos Totais (SST) expressos em mg/L e Nitrogênio Amoniacal $\left(\mathrm{N}_{-} \mathrm{NH}_{4}{ }^{+}\right.$) em $\mathrm{mg} \mathrm{N} / \mathrm{L}$.

\section{CONCLUSÕES}

$\mathrm{O}$ experimento mostrou que o reator em escala de bancada (experimental) de leito fixo e fluxo contínuo de escoamento ascendente contendo esponja de cucurbitácea como material suporte de imobilização da biomassa possui considerável eficiência para o tratamento de esgoto sanitário quando comparada com outros materiais suporte presentes na literatura, como nas etapas anaeróbias dos trabalhos de Oliveira Netto e Zaiat (2012) e Silva Neto (2016). Por isso, a bucha vegetal curcubitácea surge como opção sustentável e inovadora para o tratamento desse tipo de material antes de ser lançado nos corpos d'água ou reutilizado. 
Os parâmetros examinados no ensaio apresentaram os melhores resultados quando foi utilizado o Tempo de Detenção Hidráulica (TDH) de oito horas, onde através das análises realizadas em laboratório dos parâmetros de alcalinidade a bicarbonato, ácidos voláteis e $\mathrm{pH}$ constatou-se equilíbrio do processo de anaerobiose pela observação da produção de alcalinidade, consumo dos ácidos voláteis e estabilidade do $\mathrm{pH}$ em praticamente todo período operacional. A etapa inicial de remoção/conversão de compostos nitrogenados foi efetivada durante a anaerobiose, observada pela amonificação do nitrogênio orgânico.

Tendo em vista os resultados positivos obtidos durante esse trabalho, é recomendado que os estudos sobre a utilização da bucha vegetal curcubitácea como imobilizador de biomassa continuem sendo realizados de forma a conhecer em uma maior complexidade as propriedades desse material, tendo em vista que a base

\section{REFERÊNCIAS BIBLIOGRÁFICAS}

ABREU, S. B.; ZAIAT, M. (2008). Desempenho de reator anaeróbio-aeróbio de leito fixo no tratamento de esgoto sanitário. Revista Engenharia Sanitária e Ambiental, v. 13, n. 2, p. 181-188.

APHA. (1998). Standard methods for the examination of waste and wastewater. American Public Health association, Washington, D.C. 19th Ed.

DILALLO, R.; ALBERTSON, O.E. (1961) Volatile acids by direct tritation. Journal of the Water Pollution Control Federation, 33: 356-365.

FAZOLO, A. (2003). Determinação de parâmetros cinéticos e de transferência de massa em reator radial aeróbio-anóxico alimentado com esgoto sanitário tratado em reator anaeróbio. Tese (Doutorado) Escola de Engenharia de São Carlos, Universidade de São Paulo.

HULTON, G.; WORLD HEALTH ORGANIZATION. (2012). Global costs and benefits of drinking-water supply and científica sobre essa bucha natural ainda é bastante precária. Dessa forma, aconselhase uma investigação mais aprofundada no que diz respeito à remoção e conversão das formas de Nitrogênio através do reator biológico.

Assim, outras possíveis configurações de reatores também podem ser examinadas, como a recirculação da fase líquida para diferentes razões de vazão, permitindo que as análises de nitrito $\left(\mathrm{NO}_{2}{ }^{-}\right)$e, posteriormente, nitrato $\left(\mathrm{NO}_{3}{ }^{-}\right)$ possam ser exploradas e analisadas na operação combinada anaeróbio-aeróbio, verificando mais detalhadamente os processos de nitrificação e desnitrificação do sistema. Além da recirculação, acreditase que a opção de utilizar o reator de maneira combinada com fase anaeróbia e outra aeróbia-anaeróbia pode ter resultados ainda mais significativos, proporcionando a associação dos aspectos positivos de cada forma de tratamento, otimizando o processo.

sanitation interventions to reach the MDG target and universal coverage.

IBGE - Instituto Brasileiro de Geografia e Estatística. (2000). Diretoria de Pesquisas, Coordenação de População e Indicadores Sociais, Pesquisa Nacional de Saneamento Básico.

METCALF \& EDDY. INC. (2013). Wastewater engineering: treatment, disposal and reuse. 5ed. New York, McGraw-Hill Education.

OLIVEIRA NETTO, A. P.; ZAIAT, M. (2012). Treatment of Domestic Sewage in an Anaerobic-Aerobic Fixed-bed Reactor with Recirculation of the Liquid Phase. Clean - Soil Air Water. v.40, n.9, p. 965971, 2012.

RIPLEY, L.E.; BOYLE, W.C.; CONVERSE, J.C. (1986). Improved alkalimetric monitoring for anaerobic digestion of high-strength wastes. Journal of the Water Pollution Control Federation, 58: 406-411. 
RODRIGUES, L.S.; LOPES, B. C.; LIMA, C.A.; RIBEIRO, M.C.; SANTOS, R.P.; SILVA, I.J. Tratamento de efluentes de abatedouro de frangos por meio de reator UASB seguido de filtro anaeróbio. Arquivo Brasileiro de Medicina Veterinária e Zootecnia., v.68, n.1, p.97103, 2016.

SILVA NETO, A. C. (2016). Influência da taxa de carregamento orgânico na produção de metano em reator anaeróbio de leito fixo tratando esgoto sanitário. Dissertação (Mestrado) - Programa de Pós-Graduação em Recursos Hídricos e Saneamento (PPGRHS/UFAL).

SHOW, K.Y., TAY, J.H. 1999. Water Research, 33, $1471-1481$.

SNIS - Sistema Nacional de Informações sobre o Saneamento. Diagnóstico dos serviços de água e esgotos. 2011.
SOUZA, C. F. Biodigestão anaeróbia de dejetos de suínos: obtenção de dados e aplicação no desenvolvimento de um modelo dinâmico de simulação da produção de biogás. 2001. 140 f. Tese (Doutorado em Produção Animal) Universidade Estadual Paulista, Jaboticabal, 2001.

STEVENS, D.K. (1988). Interaction of mass transfer and inhibition in biofilms. Journal of Environmental Engineering. v. 114, p. $1352-58$.

UHR, J. G. Z.; SCHMECHEL, M.; UHR, D. D. A. P. (2016). Relação entre saneamento básico no Brasil e saúde da população sob a ótica das internações hospitalares por doenças de veiculação hídrica. Revista de Administração, Contabilidade e Economia da Fundace. v.7, n.2. 